\title{
Theoretical Analysis of the Chinese PhD Human Capital Acquisition: Factors, Mechanisms and Frameworks
}

\author{
Qing Zhao \\ Tongji University, China \\ qingzhao@tongji.edu.cn
}

\begin{abstract}
The Chinese PhD human capital acquisition had a significant growth in the past two and half decades. What factors and mechanisms stimulated such a growth? In what operation frameworks was the Chinese PhD human capital produced? Very little literature documents this topic. This paper tries to rectify this deficiency by exploring market and non-market factors, mechanisms and operation frameworks of the Chinese PhD human capital acquisition in the contexts of centrally planned, transitional and market economies. It concludes that the Chinese PhD human capital acquisition is an interaction process of market factors with policy release and institutional transition. In this process, domination of the government plan mechanism is gradually being transferred to market mechanisms through policy regulation. The supply-, demand-and institutional constraints co-exist in the Chinese PhD human capital production which has its own characteristics in its rationale and its output depends not only on its demands and inputs but on its transfer technology. The author suggests reducing the tension between market and non-market mechanisms, more market-oriented reforms should be made, more inputs should be invested, and more measures should be taken to update the transfer technology of $\mathrm{PhD}$ human capital, especially learning-doing technology and peer-collaboration effects.
\end{abstract}

\section{Introduction}

China has witnessed an accelerated growth in its $\mathrm{PhD}$ human capital acquisition since 1982. The first doctoral degrees after reforming and opening-up were awarded to only 13 people in 1982; however, the number of doctorates awarded in 2007 dramatically increased to a total of 39,592, more than 3045 times growth within 25 years. [1]Why does the Chinese PhD human capital grow so fast? Or what are the factors and mechanisms that have stimulated such a robust growth? How and in what operation frameworks do market factors and mechanisms interact with non-market factors and mechanisms to influence the Chinese PhD human capital acquisition and thus form the tension between them? This paper tries to provide a tentative answer by analysing economic performances of individuals, universities as well as governments in the Chinese $\mathrm{PhD}$ human capital acquisition.

\section{Retrospect to the Chinese PhD Human Capital Acquisition}

China's PhD human capital acquisition has experienced three periods since 1978 (See Table1) .

(1)1978-1989. Following recovery of the entrance examination for higher education institutions in 1977 after the Great Cultural Revolution, China held its first $\mathrm{PhD}$ entrance examination in 1978. The first doctoral degrees after reforming and opening-up were conferred in 1982 with only 13 people awarded throughout the country. Since 1985 students admitted to be $\mathrm{PhD}$ candidates began to increase fast and since then the scale of China's $\mathrm{PhD}$ human capital production has grown year by year. The total number of doctorates awarded in this period was 4872 .

(2) 1990-1998. This period witnessed a fast growth of $\mathrm{PhD}$ human capital production due to the increasingly large demand for high quality labor force triggered by China's fast economic growth and the implementation of "rejuvenating the nation with science and education" strategies. Doctoral degrees awarded increased fast from 2000 people in 1990 to 8403 people in 1998 with a growth rate of over two times of the last period. This 9-year period harvested 37,511 doctorates.

(3) 1999-2007. An accelerated development took place in China in its $\mathrm{PhD}$ training thanks to the expanded university enrollments since 1999. The number of students admitted for doctoral degrees in 1999 reached 19,915, increasing more than 30\% against the previous year. The total number of awarded PhDs in this period reached 194,597 to its historical summit, more than 5 times bigger than the previous period. In this period, the number of $\mathrm{PhD}$ graduates of the latest 4 years from 2004 to 2007 reached 128,834, almost double that of the previous 5-year period from 1999 to 2003, which shows the fastest development in the Chinese $\mathrm{PhD}$ education.

Since 1982 the total number of awarded PhDs has amounted to 236,980, more than half of which were awarded in the latest 5 years.

Table 1. Three Periods of the Growth of Doctoral Degrees Awarded in China

\begin{tabular}{|l|c|c|}
\hline Time Periods & $\begin{array}{l}\text { Number of } \\
\text { Years }\end{array}$ & $\begin{array}{l}\text { Total of Awarded } \\
\text { Doctoral Degrees }\end{array}$ \\
\hline $1982-1989$ & 8 & 4872 \\
\hline $1990-1998$ & 9 & 37511 \\
\hline $1999-2007$ & 9 & 194597 \\
\hline Total & 26 & 236980 \\
\hline
\end{tabular}


Data Sources: Essential Statistics of Education in China - by Dept. of Development \& Planning, Ministry of Education

\section{Features of the Chinese Higher Education market}

The market for higher education has some distinctive features that differentiate this sector from others [2], [3].

First of all, most universities allocate places to students by administrative rationing, using selective exams to determine university admission. Then, the performance or quality of universities depends positively on the ability or human capital of their students, which makes higher education provision a case of customer-input technology, as described by Rothschild and White [4]. Furthermore, many higher education institutions are non-profit maximizers and their objectives are sometimes difficult to determine. As James [5] suggests, if colleges and universities have a single-valued objective function, it is akin to "prestige maximization". Lastly, higher education in and of itself is a kind of quasi-public goods or priceexcludable public goods, which partially shares properties and features of both public goods and private goods [6]. Therefore, the production of higher education products is determined by market factors in addition to being adjusted and partially financed by governments. It is exactly on this feature of higher education that my analysis of factors affecting $\mathrm{PhD}$ human capital production develops in two facets: market factors and non-market factors.

Besides sharing the common features above, the Chinese higher education market has the following extra characteristics distinguished from those of Western countries:

Firstly, China's private universities do not have $\mathrm{PhD}$ programs even though private higher education in China developed quickly. Therefore $\mathrm{PhD}$ human capital production only goes in public universities. Secondly, competition for resources of PhD human capital production only takes place among public universities. Thirdly, with regard to education budget, although multiple fund channels have been opened up, governmental finance allocation is still the major source, especially for education of graduates including masters and PhDs. Colleges or universities directly controlled by the central government are mainly funded by the central financial pool. Colleges or universities controlled by local governments are supported by local finance. Moreover, the Chinese higher education market is a typical supply-side constrained market, that is, currently China cannot supply adequate high-quality higher education to meet the needs of $\mathrm{PhD}$ applicants because of its insufficient education resources or inputs [7]. Lastly, Chinese PhD education has three typical characteristics: a) the length of study for a $\mathrm{PhD}$ degree varies from 3 to 5 years. Generally it is 3 years but usually about 4 years for the in-the-service students unless a PhD student suspends his schooling temporarily or abandons his study. b) Currently there are two kinds of enrollments for $\mathrm{PhD}$ candidates: state-planned $\mathrm{PhD}$ students and non-state-planned $\mathrm{PhD}$ students. The tuition fee of the former comes from central government and the university in which they are studying, while that of the latter is sponsored by the institutions for which $\mathrm{PhD}$ students are serving or will serve after graduation. It could also be paid by the $\mathrm{PhD}$ students themselves. c) There is no loan market for PhD students.

\section{Chinese PhD Human Capital Acquisition: Market Factors}

Market factors are composed of those of supply and those of demand to influence or be involved in the Chinese $\mathrm{PhD}$ human capital production.

\subsection{Individual's Demands for the $\mathrm{PhD}$ Human Capital}

The demand for $\mathrm{PhD}$ human capital can be divided into two categories: individual demand and market demand. There are two kinds of individual demands: a master-degree holder's demand for $\mathrm{PhD}$ human capital (Di1) and an employer's demand for PhD human capital (Di2).

A master-degree holder's demand for $\mathrm{PhD}$ human capital is influenced or determined by the following factors:

(1) Employment rate of master-degree holders (Re). Supposing there are only three options for a graduate of master's degree after graduation: finding a job in the labor market, further study for a PhD or going abroad. If there is no proper employment opportunity, that is, if the competition for a job position is terribly fierce and there is no opportunity to go abroad as well, a master-degree graduate will intend to choose his further study for a $\mathrm{PhD}$. The employment rate of graduates (Masters and PhDs) refers to the ratio (in percentage) of the total number of graduates employed (E) to the total number of graduates $(\mathbf{G})$ in that statistical year:

$$
\mathbf{R e}=\mathbf{E} / \mathbf{G} \times \mathbf{1 0 0 \%}
$$

(2) Price of master human capital or wage rate of master degree holders in the labor market $(\mathbf{P m})$. If the current wage level of a master degree holder is higher than the individual's expected wage level, or if current wage level of a PhD holder is lower than his expected wage level, he is likely to choose to work other than study for a doctoral degree.

(3) Price of PhD human capital (Pd), which refers to the margin of expected lifetime earnings minus expected private cost for a doctoral degree. 
a) Expected Private Cost (Cp). It refers to the financial resources from an individual himself and his family. Lots of studies (Bershadke, A.H., 1998, et al) [8] found that private costs appeared to be a barrier to higher education.

An individual must spend money and time preparing the $\mathrm{PhD}$ entrance examination, named Cost for Exams (Ce), including fees for information searching, registration, reference books and tuition. If he has been enrolled to be a $\mathrm{PhD}$ candidate, he will give up opportunities to earn money (earning forgone) (Opportunity Cost, Co) (Pei, J.S., Yuan, L.Q. and Zhao, Z.Y., 2002) [9], and in his on-campus life, he should also spend money on textbooks, additional transportation, living and boarding, here called Cost for In-School Living (Cs).

So Total Private Cost for individual PhD human capital $\mathbf{C p}$ equals the sum of Cost for Exams (Ce), Opportunity Cost (Co), Cost for In-School Living (Cs) and Tuition Fee $(\mathbf{C t})$, which can be denoted by the following equation:

$\mathbf{C p}=\mathbf{C e}+\mathbf{C o}+\mathbf{C s}+\mathbf{C t}$

It can also be written as:

$$
\mathbf{C p}=\mathbf{C d}+\mathbf{C i d}
$$

Where $\mathbf{C d}=\mathbf{C e}+\mathbf{C s}+\mathbf{C t}$ is direct cost, $\mathbf{C i d}=\mathbf{C o}$ is indirect cost.

If the prices of $\mathbf{C p}, \mathbf{C e}, \mathbf{C o}, \mathbf{C t}, \mathbf{C s}, \mathbf{C d}$, $\mathbf{C i d}$ are respectively indexed by $\mathbf{P p}, \mathbf{P e}, \mathbf{P o}, \mathbf{P t}, \mathbf{P s}, \mathbf{P d}$ and Pid, then the equations (2) and (3) can be substituted respectively by equations (4)and (5)

$$
\text { Or } \quad \mathbf{P p}=\mathbf{P d}+\mathbf{P i d}
$$

b) Expected Lifetime Earnings (Ee). Human capital theory demonstrates that more years of schooling will lead to higher earnings. So earnings expectation is an important financial incentive to a master-degree holder's decision to enroll in a $\mathrm{PhD}$ program. To an individual master-degree holder, the prerequisite for him to decide to be enrolled in a $\mathrm{PhD}$ program is that Expected Lifetime Earnings should be bigger than Expected Private Cost. Otherwise, he will choose to enter the labor market other than being enrolled in a $\mathrm{PhD}$ program. And thus

$$
\mathbf{P d}=\mathbf{E e}-\mathbf{C p}>0
$$

(4) Acceptance Rate ( $\mathrm{Ra})$. It refers to the ratio of the number of examinees who have been successfully enrolled in doctoral programs to the total number of examinees in an annual $\mathrm{PhD}$ entrance examination or the ratio of the number of admitted students to the number of applicants. If proportion of enrollment in a given year is higher or set higher by expansion policy from the Education Ministry of China than the previous year, an examinee is more likely to be enrolled. And thus an examinee would be more likely to be enrolled in a PhD program.

$$
\mathbf{R} \mathbf{a}=\mathbf{N}_{\mathbf{u}}{ }^{\mathrm{Adm}} / \mathbf{N}_{\mathbf{u}}{ }^{\mathrm{App}}
$$

$\mathbf{N}_{\mathrm{u}}{ }^{\text {Adm }}$ and $\mathbf{N}_{\mathrm{u}}{ }^{\text {App }}$ are respectively the number of admitted students and the number of applicants of a university (u).

Besides the factors above, a master degree holder's preference (Pr), family background (F) and some other unobservable factors ( $\boldsymbol{\varepsilon}$ ) also influence his decision-making of whether he will be enrolled into a PhD program.

From above analysis, I hold that an individual master-degree holder's demand is the function of the factors discussed above, namely,

$$
\text { Di1= f (Re, Pm, Pd, Ra, Pr, F, \&) }
$$

The second demand for $\mathrm{PhD}$ human capital is from an individual employer. This demand depends on the quantity of $\mathrm{PhD}$ holders employed by this employer if the quality of $\mathrm{PhD}$ holders' human capital is given.

\subsection{Market Demand for PhD Human Capital}

The total market demand (D) for $\mathrm{PhD}$ human capital depends on the quantity of all master-degree holders' demand for PhD human capital (Dm1) and all employers' demand for PhD human capital (Dm2). Supposing there are $\mathbf{m}$ master-degree holders for their doctoral degrees each year, then in $\mathbf{t}$ years,

$$
\operatorname{Dm} 1=\sum_{\mathrm{t}=1}{ }^{\mathrm{T}} \mathbf{m}_{\mathrm{t}}
$$

Supposing there are j employers and the1st, 2nd..., and jth individual employers who want to employ $\mathrm{K}_{1(1)}, \quad \mathrm{K}_{2(1)} \quad \ldots \mathrm{K}_{\mathrm{j}} \quad$ (1) $\quad$ doctor-degree holders respectively in the first year, $K_{1(2)}, K_{2(2)} \ldots K_{j}$ (2) respectively in the second year, ..., and $\mathrm{K}_{1(\mathrm{t})}$, $\mathrm{K}_{2(\mathrm{t})} \ldots \mathrm{K}_{\mathrm{j}(\mathrm{t})}$ respectively in the th year, thus the total market demand in t years will be as follows

$$
\mathbf{D m} 2=\sum_{\mathbf{t}=\mathbf{1}}^{\mathbf{T}} \sum_{\mathbf{i}=\mathbf{1}}^{\mathbf{j}} \mathbf{K}_{\mathbf{i} \mathbf{t}}
$$

So the aggregate market demand for doctoral degrees (PhD human capital)(D) will be the sum of total Dm1 and total Dm2 minus their sharing part D'

$$
\mathbf{D}=(\mathbf{D m} 1+\mathbf{D m} 2)-\mathbf{D}
$$

\subsection{Supply of PhD Human Capital}

Supply or inputs in the $\mathrm{PhD}$ human capital can also be divided into two categories: individual supplies and market supplies. There are four kinds of individual supplies. The first one is the inputs by PhD students (P1) which are composed of $\mathrm{PhD}$ students' labour (Ld), and capital (Cd) (physical capital (Pc) and initial human capital stock (Hdi)). The second supply is the inputs by a university (P2), which are composed of labour input ( $\mathbf{L u})$, and capital inputs $(\mathbf{C u})$ (the university's human capital $(\mathbf{H u})$ and physical capital $(\mathbf{P u})$ ). The third supply is the social inputs or social capital in a PhD's human capital production (P3). The fourth supply, which I hold, is Human Capital Transfer Technology (T), which entails the integration of teaching-administrative technology (T1), learning-doing technology (T2) and peer-collaboration effects (T3). 


$$
\mathbf{T}=\mathbf{T} 1 \times \mathbf{T} 2 \times \mathbf{T} 3
$$

Market supply of $\mathrm{PhD}$ human capital depends on all those factors which in turn influence the supply of individual universities. Besides the inputs used to produce $\mathrm{PhD}$ human capital and the available technology, the supply of $\mathrm{PhD}$ human capital in a market also depends on the number of sellers, namely, the number of $\mathrm{PhD}$ holders (Qd) and universities (Qu).

$\mathbf{S m}=\mathbf{f}(\mathbf{P} 1, \mathbf{P} 2, \mathbf{P} 3 ; \mathbf{Q d}, \mathbf{Q u} ; \mathbf{T})$

Supposing the quality of $\mathrm{PhD}$ human capital is given, the quantity of $\mathrm{PhD}$ human capital a university produces annually will depend on the number of its doctoral degrees conferred in that year. Supposing there are $\mathrm{n}$ employers and the1st, 2nd..., and nth universities which confer $\mathrm{q}_{1(1)}, \mathrm{q}_{2(1)} \ldots \mathrm{q}_{\mathrm{n}(1)}$ doctor degrees respectively in the first year, $\mathrm{q}_{1(2)}, \mathrm{q}_{2(2)} \ldots \mathrm{q}_{\mathrm{n}(2)}$ respectively in the second year, ..., and $\mathrm{q}_{1(\mathrm{t})}$, $\mathrm{q}_{2(\mathrm{t})} \ldots \mathrm{q}_{\mathrm{n}}(\mathrm{t})$ respectively in the th year, thus the aggregate PhD human capital supply in China Sm in $\mathrm{t}$ years will be as follows

$$
\mathbf{S m}=\sum_{\mathbf{t}=1}^{T} \sum_{\mathbf{i}=\mathbf{1}}^{\mathbf{n}} \mathbf{q}_{\text {i }}
$$

\section{Chinese PhD Human Capital Acquisition: Non-Market Factors, Operation Frameworks and Mechanisms}

As a product of higher education market, Chinese $\mathrm{PhD}$ human capital is produced in the background of the Chinese institutional transition, located within the process of the reform of a higher education system.

\subsection{Chinese PhD Human Capital Acquisition: Institutional Context}

Since the late 1970s, China has started to implement new state policies of economic reform by opening up to the outside world, aiming at accelerating its economic development. This has initiated the process of transition from a centrally planned economy to a market economy. This process has a strong impact on the Chinese universities. With the labor market gradually established in China, the development and allocation of human capital mainly goes by market mechanisms other than the governmental plan. In such a background, higher education institutions need to gear their programs to meet the needs of the labor market. And also, the economic reforms coincide with the information revolution which led the world into a new era of a knowledge-based economy. The ability to generate, accumulate, deploy, and utilize knowledge information has become crucial for development. Furthermore, information economy has formed an irresistible and irreversible trend of internationalization of higher education. Thus, the necessity of reforming Chinese higher education system, which used to be a part of the centrally planned economy, should be put on the agenda.

\subsection{Operation Framework and Mechanisms of Chinese PhD Human Capital Acquisition in the Context of the Centrally Planned Economy}

The Chinese higher education in the 1980s and 1990s maintained almost the same framework and operation mechanisms as those in the context of the centrally planned economy. In such an operation framework, the state policies dominated almost all aspects of $\mathrm{PhD}$ human capital production and distribution while the market mechanism lost almost all its effects in adjusting $\mathrm{PhD}$ human capital production and allocation. The only place in which there was somewhat the shadow of market mechanism was the competition among examinees in the $\mathrm{PhD}$ entrance examination. Although the competition existed, however, it was limited and very weak, especially in the initial stage of $\mathrm{PhD}$ education. In the three successive years of 1981 to 1983, PhD enrollment did not even reach the numbers planned because the resources of entrants were insufficient. So the state plan was the only mechanism in such an operation framework (See Figure 1).

Figure 1. The Operation Framework for the Chinese PhD Human Capital Acquisition in the Centrally Planned Economy

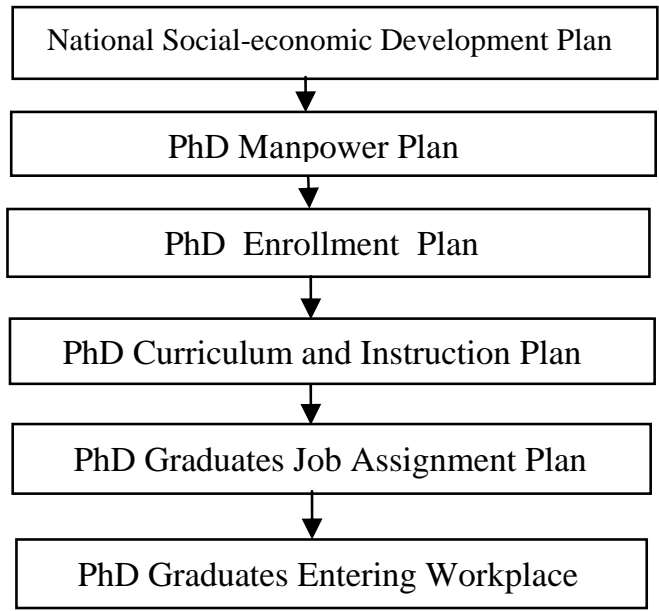

\subsection{Operation Framework and Mechanisms of Chinese PhD Human Capital Acquisition in the Context of the Market Economy}

In the market economy, the interaction of demand and supply is fundamental to $\mathrm{PhD}$ human capital model. It influences the wage rate of $\mathrm{PhD}$ graduates and expected benefits from PhD education as well as the demand for $\mathrm{PhD}$ human capital. This results in the outputs of PhD human capital from universities 
to labor market. The performance and competiveness of $\mathrm{PhD}$ human capital in the labor market serves as a feedback to a university's PhD human capital production. However, the market is not an omnipotent and a panacea. Market failure often happens in both the higher education market and the labor market. It is clear then that the government should still play an important role in this market context. The Chinese government exerts its impacts on $\mathrm{PhD}$ human capital production mainly through policy tools, including a) macro-economic policies of influencing the total demand and labor market demand for PhD human capital, and b) educational and funding policies, such as the policy of expanding $\mathrm{PhD}$ enrollment, and the policy of financing the programs of national priorities; c) a quality control system for $\mathrm{PhD}$ education such as evaluating $\mathrm{PhD}$ disciplines and ranking $\mathrm{PhD}$ programs every three years. In such a framework, the allocation mechanisms are comprised of two aspects: market mechanisms and the mechanism of government policies, which is illustrated as follows (See Figure 2):

Figure 2. The Operation Framework and Mechanisms of the Chinese PhD Human Capital Acquisition in the Context of the Market Economy

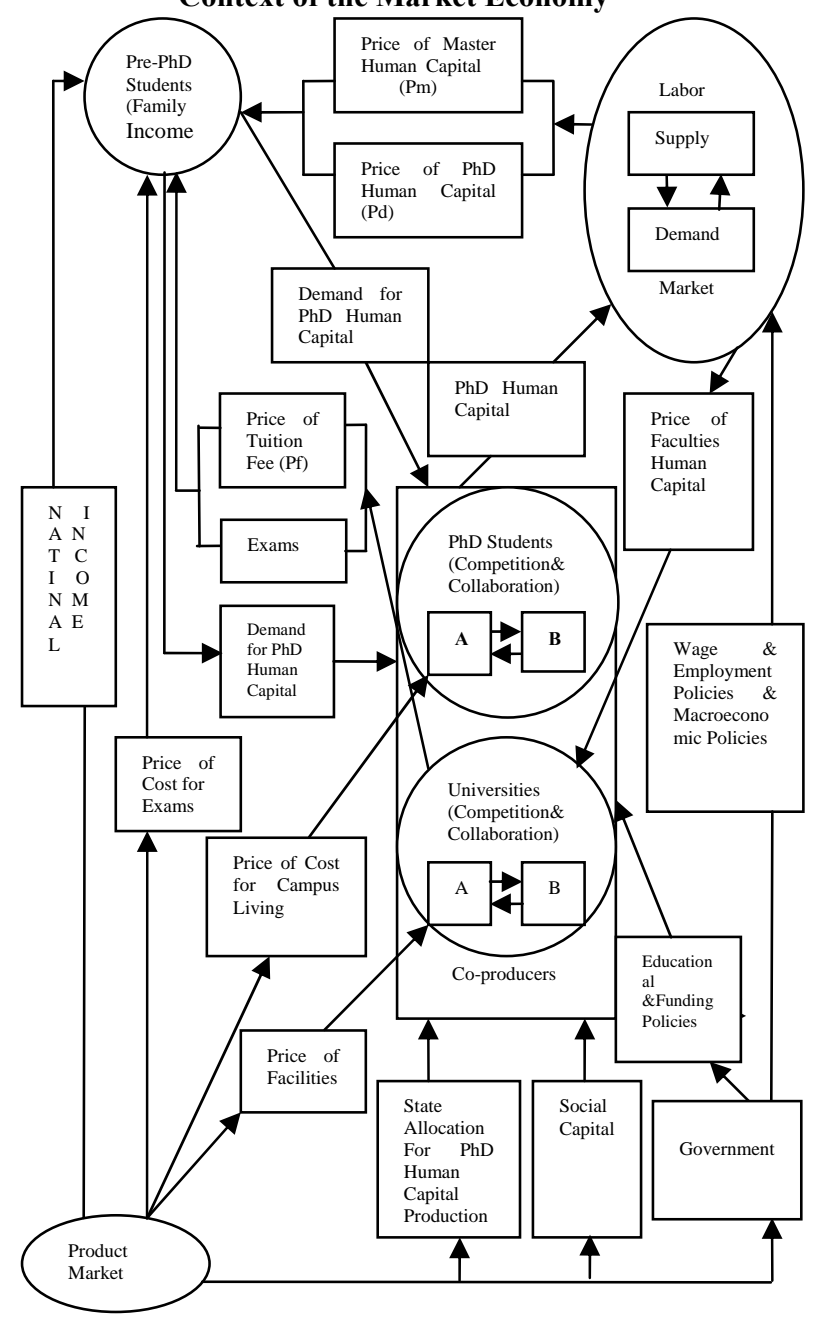

Prices: The mechanism of price works as follows: to pre-PhD students, the price of master's human capital or wage rate of master-degree holders in the labor market $(\mathbf{P m})$ and the price of $\mathrm{PhD}$ human capital $(\mathbf{P d})$ are two determinants in whether an individual master-degree holder will be enrolled in a $\mathrm{PhD}$ program or not. To an inschool PhD student, if the price of his inputs $(\mathbf{P} 1)$ is too high for him, he will probably choose to drop out from school. To a PhD graduate, if the price of $\mathrm{PhD}$ human capital or wage rate of $\mathrm{PhD}$ graduates in the labor market is much low beyond his expectation, he will probably give up on entering the job market. As such he may choose, for example, to go abroad. To a university, if its budget for $\mathrm{PhD}$ human capital production is given, the price of its inputs in $\mathrm{PhD}$ human capital production will influence the number of $\mathrm{PhD}$ students it can enroll. That is, given the constraint of school budget, if the price of university inputs increases or decreases, taking the quality and other factors as given, the enrollment rate will decrease or increase. Taking number of enrollment and other factors as given, the quality of $\mathrm{PhD}$ human capital will decline or increase.

Exams: Akin to Romero and Del Rey [3], I also hold the belief that exams are a mechanism for Chinese universities to select the best students among those who are willing to attend a $\mathrm{PhD}$ program in a university. Universities set up a minimum score to accept those whose scores are equal to or higher than the minimum score. Supposing that exam technology is able to perfectly reveal a student's ability, which means there is a oneto-one relationship between the standard of admission and the ability of the least number of students accepted into the university $\mathrm{PhD}$ programs. Thus, students who obtain a score higher than the minimum established by the university will add more human capital to the whole initial $\mathrm{PhD}$ human capital stock of a university. Assuming the admission standard (the minimum admission score) is uniform across universities, a university with more entrants whose scores are much higher than minimum score will have more initial doctoral human capital.

Competition: Competition also plays a role in allocating resources for $\mathrm{PhD}$ human capital production. Competitions take place in the following areas: firstly there is a competition among examinees in the $\mathrm{PhD}$ entrance examination, through which universities will select students for their doctoral programs according to their admission standards. Secondly, this competition also carries through universities with the same or similar doctoral programs. They not only compete for resources of talented or qualified pre-PhD students and excellent faculties, especially prominent professors, but also for the government funding as well as the rank of 
their doctoral programs. Moreover, competition mechanism also works among $\mathrm{PhD}$ students, their supervisors and other teachers who are involved in PhD human capital production.

Policies: Policy mechanism can complement the deficiencies and failure of market mechanism by adjusting the university performances, the behaviors of families, pre-PhD students, $\mathrm{PhD}$ students or employers so as to influence the supply of or demand for $\mathrm{PhD}$ human capital.

Other Mechanisms: The Chinese PhD human capital acquisition is a systematical activity, which not only involves universities, students, families and governments but also is related to the whole society in a broad sense. This not only includes competition but also has collaborations and peer effects. The mechanisms listed above are evidently the main ones.

\subsection{Current Operation Framework and Mechanisms of Chinese PhD Human Capital Acquisition in the Context of Transitional Economy}

The current operation framework and mechanisms of the Chinese $\mathrm{PhD}$ human capital acquisition, in comparison with those in the context of market economy, besides sharing their common mechanisms, have the following different features:

Plans still exist as a mechanism of resources allocation. Although China had declared in 2003 that the market economy system has already been shaped fundamentally, in terms of the higher education dimension, however, the shadow of planned economy still exists in the following three aspects:

(1) Plan for PhD enrollment quotas. As a part of educational plan, the $\mathrm{PhD}$ enrollment quotas are yearly distributed to universities by the Education Ministry of China, which means that universities themselves have no priority to decide the number of PhD enrollments according to their resources.

(2) Plan for PhD programs and disciplines. Each newly planned $\mathrm{PhD}$ program and discipline from universities must be evaluated and approved by the Education Ministry of China.

(3) Double tracks in tuition fees. This is another distinguished feature in the current framework of $\mathrm{PhD}$ human capital acquisition different from that of regular market economy context.

The above features will result in the following problems to the Chinese $\mathrm{PhD}$ human capital acquisition: The government plan for the $\mathrm{PhD}$ enrollment quotas would restrain the effective market demand for $\mathrm{PhD}$ human capital from pre-PhD students if it could not reflect such a demand. That is, besides supply-constraint and demand constraint, the government plan is also a constraint added to the Chinese PhD human capital acquisition.
The government plan for $\mathrm{PhD}$ programs and disciplines will bring universities into fierce competition for new PhD programs and disciplines. On the one hand, the universities will tend to forget the fact that the demand and criteria of $\mathrm{PhD}$ human capital which are determined by the labor market other than being set by governments. On the other hand, such a competition is more likely to result in rent seeking and corruption.

\section{Conclusion}

The purpose of this study was to explore the tension between market and non-market mechanisms by analysis of the market and non-market factors which stimulate the significant growth of the Chinese $\mathrm{PhD}$ human capital acquisition. From the analysis above, I have drawn the following conclusions:

(1) The Chinese PhD human capital acquisition is an interaction process of market factors with institutional transition and policy release. This process is composed of four periods: the pre-period, the period in the context of centrally planned economy, the period in the context of transitional economy and the period in the context of market economy. This process can be clearly seen from the

Figure 3. The Operation Framework and Mechanisms of the Chinese PhD Human Capital Acquisition in the Context of the Transitional Economy

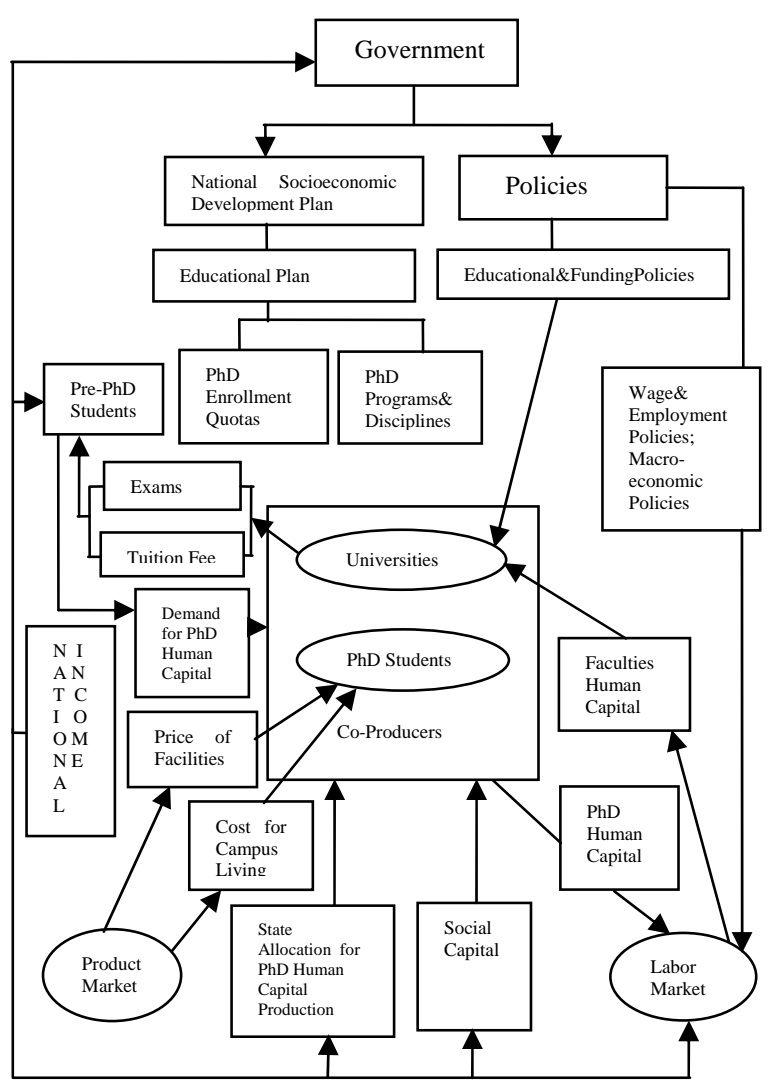


following equations of production function of $\mathrm{PhD}$ human capital:

$\mathbf{Y}=\mathbf{f}(\mathbf{X})=\mathbf{f}(\mathbf{X m}, \mathbf{X n o n}-\mathrm{m})=\mathbf{f}(\mathbf{D m}, \mathbf{S m} ; \mathbf{I}, \mathbf{P}, \mathbf{B})$

Where $\mathbf{X}$ denoting the aggregate factors determining or stimulating the Chinese $\mathrm{PhD}$ human capital acquisition, which consists of the market factors $\mathbf{X m}$, and the non-market factors $\mathbf{X n o n - m}$, is the variable of the aggregate output of the Chinese $\mathrm{PhD}$ human capital $\mathbf{Y}$. Xm is the sum of all market factors that influence total market demand $\mathbf{D m}$ and total market supply $\mathbf{S m}$. Xnon-m is the sum of all non-market factors including institutional transition $\mathbf{I}$, government policy $\mathbf{P}$, and other non-market factors 乃. This equation expresses that the total $\mathrm{PhD}$ human capital output is the function of variables of market demand, market supply, institutional transition, government policy and other non-market variables.

(2) Following the institutional transition and policy release, domination of the government plan mechanism in the $\mathrm{PhD}$ training is gradually being transferred to the domination of regular and mature market mechanisms regulated by the government policies. In the context of centrally planned economy, plan is the dominant mechanism in the Chinese $\mathrm{PhD}$ human capital acquisition. In the context of transitional economy, more and more market mechanisms were generated and market became the major force while plan fell to be a minor mechanism in the $\mathrm{PhD}$ human capital production. In the context of market economy, market mechanisms and the mechanism of government policies jointly work together in the Chinese $\mathrm{PhD}$ human capital production.

(3) The supply-constraint, demand-constraint and institutional constraint co-exist in the Chinese $\mathrm{PhD}$ human capital acquisition. The supply constraint mainly results from the insufficient inputs by governments and universities, and also from the lack of rich private and social inputs. Demand constraint mainly comes from pre-PhD students' (masterdegree holders') and in-school PhD students' financial difficulty when they attempt to acquire or do acquire their $\mathrm{PhD}$ human capital. Even though there is no tuition fee for nationally planned $\mathrm{PhD}$ students, such a case still exists and thus constrains the Chinese PhD human capital acquisition. There is also a constraint from the current Chinese education system, which means that the existing shadow of centrally planned economy in $\mathrm{PhD}$ education provision is a constraint for mechanisms of market supply and demand to play an effective and efficient role in the Chinese $\mathrm{PhD}$ human capital production.

(4) $\mathrm{PhD}$ human capital has its own characteristics in its production rationale and production factors, which are different from those of other goods and services, and also from those of purely private goods and purely public products. These characteristics are: a).The relationship between $\mathrm{PhD}$ students and their university in doctoral human capital production is costumers-producer (producers-customer), coproducers, and double sellers. b).The teachingadministrative technology, learning-doing technology and peer-collaboration effects constitute the human capital transfer technology in $\mathrm{PhD}$ human capital production. c) Two heterogeneous demands for $\mathrm{PhD}$ human capital, one of which is from pre$\mathrm{PhD}$ students before $\mathrm{PhD}$ human capital production begins and the other is from employers after $\mathrm{PhD}$ human capital production concludes, are different from one homogeneous demand for other goods and services. d). The most obvious characteristic in $\mathrm{PhD}$ human capital production is its customers' ( $\mathrm{PhD}$ students) inputs. e).As a quasi-product, $\mathrm{PhD}$ human capital shares some common aspects with the public products and private goods.

(5) The output of PhD human capital including its quantity and quality depends not only upon its demands and inputs but also on the transfer technology of human capital.

The above conclusions have the following policy implications:

(1) In order to lessen the institutional-constraint in the Chinese $\mathrm{PhD}$ human capital production, the Chinese government should make more marketoriented reforms in the Chinese higher education sector, especially in its $\mathrm{PhD}$ training, to build a fair and competitive higher education market symmetrical to the Chinese labor market.

(2) In order to reduce the supply-constraint and demand-constraint, more inputs should be invested into the Chinese PhD human capital production. These inputs can be funded with more expenditure from governments and universities, more coinvestments by universities and businesses, or more donations from other social sources.

(3) Universities with PhD programs should not only improve their teaching-administrative technology, but also update and increase their $\mathrm{PhD}$ candidates' learning-doing technology and peercollaboration effects so as to improve the quality of PhD human capital to better meet the employers' demands in labor market.

\section{References}

[1] National Bureau of Statistics of China, "China Statistical Yearbook 2008", China Statistics Press, China, Sept., 2008, 20-2.

[2] Whinston, G. C. "Subsidies, Hierarchy and Peers: The Awkward Economics of Higher Education", Journal of Economic Perspectives Vol. 13, No1, 1999, P13-36.

[3] Romero, L. and Del Rey, E., "Competition between Public and Private Universities: Quality, Prices and Exams", University Carlos III de Madrid: Working Paper 04-64 Economics Series 23, Nov. 2004. 
[4] Rothschild, M. and White, L. "The Analytics of the Pricing of Higher Education and Other Services in Which Customers Are Inputs”, Journal of Political Economy Vol. 103, 1995, P573-586.

[5] James, E., "Decision Processes and Priorities in Higher Education." The Economics of American Universities. Hoenack, Stephen A. and Eileen L. Collins, eds. Buffalo, NY State University of New York Press, 1990.

[6] Samuelson, P. A., "The Pure Theory of Public Expenditure", The Review of Economics and Statistics, Vol.36, No. 4, Nov.1954, P387-389.

[7] Zhou, J., "Insufficient Educational Resources and Large Educational Demands Co-exist in the Chinese Education", China Education Daily, March10, 2009.

[8] Bershadke, A.H., "The Effect of Financial Incentives on Postsecondary Enrollment.” Doctoral Dissertation. University of Wisconsin-Madison, 1998, P. 111.

[9] Pei, J. S., Yuan, L.Q. And Zhao, Z.Y., “An Economic Analysis for Graduate Education Investment”, Chinese Soft Science, 2002, No.2. 